\title{
AQUARIUS: A Passive/Active Microwave Sensor to Monitor Sea Surface Salinity Globally from Space
}

\author{
David Le Vine ${ }^{\mathrm{a}}$, Gary S.E. Lagerloef ${ }^{b}$, F.Raul Colomb ${ }^{\mathrm{c}}$, Yi Chao ${ }^{\mathrm{d}}$ \\ "NASA/Goddard Space Flight Center, Code 975, Greenbelt, MD 20771 \\ ${ }^{b}$ Earth and Space Research, 1910 Fairview Ave E, Suite 210, Seattle WA 98102 \\ ${ }^{\circ}$ Comision Nacionales de Actividades Espaciales (CONAE), Buenos Aires, AR \\ NASA Jet Propulsion Laboratory, 4800 Oak Grove Drive, Pasadena, CA 91109
}

\begin{abstract}
Salinity is important for understanding ocean dynamics, energy exchange with the atmosphere and the global water cycle. Existing data is limited and much of the ocean has never even been sampled. Sea surface salinity can be measured remotely by satellite and a three year mission for this purpose called Aquarius/SAC-D has recently been selected by NASA's Earth System Science Pathfinder (ESSP) program. The objective is to map the salinity field globally with a spatial resolution of $100 \mathrm{~km}$ and a monthly average accuracy of 0.2 psu. The mission, scheduled for launch in 2008, is a partnership of the United States National Aeronauatics and Space Agency (NASA) and the Argentine Comision Nacional de Actividades Epaciales (CONAE).
\end{abstract}

Keywords: sea surface salinity, remote sensing, microwave radiometer, microwave scatterometer

\section{INTRODUCTION}

Salinity and temperature determine sea water density. Hence, changes in salinity influence ocean circulation and associated heat transport. Changes in ocean salinity reflect variations in freshwater flux and thus are associated with fundamental processes that couple the ocean with the global water cycle and influence climate. The existing conventional salinity database is to sparse to resolve key processes on a seasonal to interannual time scale or to establish the freshwater flux at the air-sea interface. For example, dividing the ice-free ocean into 1 degree squares, one finds that about $25 \%$ has never been sampled and more than $73 \%$ has fewer than 10 samples (Koblinsky et al, 2003; Lagerloef, Swift and Le Vine, 1995). The sparse data is primarily a reflection of the limitations of surface sampling. However, sea surface salinity can be measured remotely using microwave sensors operating near $1.4 \mathrm{GHz}$ (L-band) providing the potential for global monitoring from space (Swift and McIntosh, 1983; Lagerloef, Swift and Le Vine, 1995).

Salinity has a measurable effect on the thermal emission from sea water when observed at the long wavelength end of the microwave spectrum. The emission is a function of salinity and the physical temperature of the water (Lagerloef, Swift and Le Vine, 1995) and by measuring the emission (e.g. brightness temperature, $T_{B}$ ) with a microwave radiometer together with physical temperature of the water, one can deduce the salinity. This is illustrated in Figure 1 which shows brightness 
temperature, $T_{B}$, as a function of water temperature for constant values of salinity. These curves are for an ideal surface (no waves) using the model of Klein and Swift (1977) for the dielectric constant of sea water. In the remote sensing problem, the sensor measures $T_{B}$ (vertical axis) and sea surface temperature (SST) is obtained from an ancillary source (e.g. Reynolds and Smith, 1994). The change in brightness temperature to be encountered in the open ocean (shaded area) is small but measurable with modern radiometers.

The remote sensing of salinity has been demonstrated in experiments with radiometers aboard aircraft. Among the first experiments demonstrating the potential for remote sensing of salinity were those conducted in the late 1970's at NASA's Langley Research Center (Thomann, 1976; Blume et al, 1978; Blume and Kendall, 1982). Recently, measurements have been conducted with modern imaging radiometers such as the ESTAR and SLFMR (Le Vine et al, 2000a; 1998) and experiments have been conducted with an active (radar) sensor added to help correct for surface roughness ( $\mathrm{Li}$ et al, 2000; Wilson et al, 2001). Figure 2 is an example of data collected with the Lband synthetic aperture radiometer, ESTAR, during the Gulf Stream Experiment (Le Vine, et al, $2000 \mathrm{~b}$ ). This was an experiment in the Atlantic Ocean about $200 \mathrm{~km}$ east of the mouth of the Delaware River. Figure 2 shows the salinity retrieved from the L-band radiometer measurements compared with surface measurements made by the R/V Cape Henlopen (Le Vine, et al, 2000b). The salinity gradient apparent in the graph is associated with crossing the edge of a warm core eddy from the Gulf Stream. During these experiments ESTAR was mounted on the NASA Orion P-3B aircraft and in the case shown here flew over the Cape Henlopen as it sailed an east-west line at $38.65^{\circ} \mathrm{N}$ across the eddy boundary. The solid line is the salinity measured by the ship and the dashed line is the salinity retrieved with the L-band radiometer.

Aquarius is a salinity sensor to demonstrate remote sensing of salinity from space and to provide data (salinity) needed for improved understanding of ocean dynamics and climate. The Aquarius/SAC-D mission is a partnership of the USA space agency, NASA, and the Argentine space agency, CONAE. Aquarius, the salinity sensor, is being developed by NASA. The spacecraft (SAC-D) and several associated instruments are being provided by CONAE. Aquarius is dedicated to mapping salinity in the open ocean with the high accuracy needed for ocean science. The primary instrument is an L-band radiometer, but the instrument package includes an active channel (scatterometer) to assist with the correction for surface roughness.

\section{SCIENCE OBJECTIVES}

The objective of the Aquarius mission is to monitor the seasonal and interannual variation of the large scale features of the surface salinity field in the open ocean. This will provide data to address scientific questions associated with ocean circulation and its impact on climate. For example, salinity is needed to understand the large scale thermohaline circulation, driven by buoyancy, which moves large masses of water and heat around the globe. Of the two variables that determine buoyancy (salinity and temperature), temperature is already being monitored. Salinity is the missing variable needed to understand this circulation.

Salinity is also plays an important role in energy exchange between the ocean and atmosphere. In addition to the thermohaline circulation, in areas of strong precipitation, fresh water "lenses" can 
form on the surface (Sprintall and Tomczak, 1992). These are buoyant layers of water that form stable layers and insulate the water in the mixed layer below from the atmosphere. This alters the air-sea coupling (energy exchange) and can affect the evolution of intra-seasonal oscillations and monsoons in the tropics.

Salinity is also a surrogate for freshwater flux. Changes in surface salinity reflect changes in freshwater (e.g. evaporation and precipitation, and also river run-off and ice melt). Hence, a map of the global salinity field will also help to better understand the global water cycle and how it is changing.

The time and spatial scale of observations needed to improve understanding of these processes are relatively long but the salinity changes are relatively small (tenths of a psu) compared for example to processes in the coastal ocean. The goal for the Aquarius instrument is to provide global maps of the sea surface in the open ocean salinity field on a monthly basis with an average accuracy of 0.2 psu and at a spatial resolution of $100 \mathrm{~km}$.

\section{INSTRUMENT}

Aquarius is a passive/active (radiometer/radar) combination operating at L-band $(1.413 \mathrm{GHz}$ for the radiometer and $1.26 \mathrm{GHz}$ for the scatterometer). The primary instrument for measuring salinity is the radiometer. The scatterometer has been included to help correct for surface roughness (waves).

The antenna for these two instruments is a large ( 3 meter diameter) offset-fed reflector with three feeds (Figure 3). The three beams are arranged in pushbroom fashion and pointed to the side (across track) at angles with respect to nadir of 23.3, 33.7 and 41.7 degrees. The antenna is shared by both radiometer and scatterometer. In the case of the radiometer, the resolution of the three beams ranges from $62 \times 68 \mathrm{~km}$ for the inner beam to $75 \times 100 \mathrm{~km}$ for the outer beam and together they provide coverage of a swath of about $250 \mathrm{~km}$. The sensor will be in a sun-synchronous orbit with a $6 \mathrm{pm}$ (ascending) equatorial crossing and altitude of $650 \mathrm{~km}$. This orbit places the spacecraft close to the day-night terminator and the beams will point to the night-time side to avoid sun-glint and provides good coverage of a potential calibration site in the Antarctic. The $250 \mathrm{~km}$ swath will permit complete coverage of the globe in 7 days. The goal is monthly maps but in order to achieve the goal of 0.2 psu averaging is necessary to reduce noise (Yeuh et al, 2001).

The radiometer will be polarimetric (measure vertical and horizontal polarization plus the third Stoke's parameter). The third Stoke's parameter (real part of the correlation between V and H polarization) has been included to help with the correction for Faraday rotation which is an important consideration at L-band (Le Vine and Abraham, 2002; Yeuh et al, 2001).

A unique feature of Aquarius is that it will include an L-band (1.26 GHz) scatterometer. The purpose of the scatterometer is to provide a correction for surface roughness (waves) which is probably the largest unknown in the salinity retrieval algorithm (Yeuh et al, 2001; Camps et al, 2004). The scatterometer and radiometer will share the same antenna with the observations interleaved in time (Yeuh et al, 2003). Each beam (feed) will have a dedicate Dicke-switching radiometer; however, there will be only one scatterometer. It will switch sequentially between 
polarization ports at each feed and then to each of the antenna feeds. The performance requirements for each of the instruments is described in Table I of Yueh et al (2003).

Achieving an accuracy of $0.2 \mathrm{psu}$ in the salinity measurement will require averaging and careful correction for geophysical sources of error (Yeuh, et al, 2001). In addition to Faraday rotation and surface roughness which have been considered specifically in the instrument design (e.g. polarimetric channels for radiometer and the scatterometer), other sources of error at L-band include emission from the atmosphere and ionosphere, and the galactic background radiation (Le Vine and Abraham, 2002; 2004; Yeuh et al, 2001). The sun is also an important source of undesired signal at L-band. Achieving the desired accuracy will require careful attention to instrument design (stability and noise) together with modeling to account for the geophysical sources of error. To aid in calibration provisions are being made to rotate the spacecraft to look at the cold sky and to collect data from an extensive network of surface sensors.

\section{PARTNERSHIP}

The salinity mission is a partnership of the United States space agency, NASA, and the Argentine space agency, CONAE. The formal name of the mission is Aquarius/SAC-D. Aquarius, is the salinity sensor described above. It is being developed in the US by a team at the Goddard Space Flight Center (GSFC) and Jet Propulsion Laboratory (JPL) that is well integrated between the two centers. Goddard has primary responsibility for the radiometer and JPL primary responsibility for the scatterometer and overall project integration. The spacecraft (SAC-D) plus integration and testing are being provided by CONAE. CONAE will also provide several associated instruments. These are still being defined but most likely will include an infrared camera to detect forest fires, a high resolution visible camera and a microwave radiometer at $37 \mathrm{GHz}$ and also possibly $24 \mathrm{GHz}$. The microwave radiometer will provide measurements of rain, wind and sea-ice along the Aquarius swath. In addition, the payload will include an atmospheric occultation experiment from Italy and a French experiment to monitor space debris. The launch will be provided by NASA and CONAE will provide the ground station and mission operations. The principle investigator is Gary Lagerloef of Earth and Space Research.

\section{REFERENCES}

1. Blume, H-J C., B.M. Kendall and J.C. Fedors, "Measurements of ocean temperature and salinity via microwave radiometry”, Boundary Layer Met., 13, 295, 1978

2. Blume, H-J C. and B.M. Kendall, "Passive microwave measurements of temperature and salinity in coastal zones", IEEE Trans on Geosci and Remote Sens., GE-20, 394-404, 1982.

3. Camps, A.; Font, J.; Vall-llossera, M.; et al., "The WISE 2000 and 2001 field experiments in support of the SMOS mission: sea surface L-band brightness temperature observations and their application to sea surface salinity retrieval”, IEEE Trans. Geosci. Remote Sens., 42 (\#4),804 823, 2004.

4. Klein, L.A. and C.T. Swift, "An impro0ved model for the dielectric constant fo sea water at microwave frequencies”, IEEE Trans. Antennas and Propag., AP-25, 104-111, 1977.

5. Koblinsky, C.J., P. Hildebrand, D. Le Vine and F. Pellerano, "Sea surface salinity from space: Science goals and measurement approach", Radio Science, 38 (\#4), 2003. 
6. Lagerloef, G.S.E., 2000, website: http://www.esr.org/, (click on Research and then SSIWG)

7. Lagerloef, G.S.E, C. Swift, D. Le Vine, 1995, Sea surface salinity: The next remote sensing challenge, Oceanogr. 8, 44-50.

8. Le Vine, D.M., M. Kao, R. Garvine and T. Sanders, "Remote sensing of ocean salinity: Results from the Delaware Coastal Current experiment", J. Atmos. Oceanic Tech. 15, 1478-1484, 1998.

9. Le Vine, D.M., J.B. Zaitzeff, E.J. D'Sa, J.L. Miller, C. Swift, M. Goodberlet, “Sea surface salinity: Toward and operational remote-sensing system, in Satellites, Oceanography and Society, edited by D. Halpern (Elsevier Science B.V.), pp 321-335, 2000a,

10. Le Vine, D.M., C. Koblinsky, S. Howden, M. Haken and M. Goodberlet, "Salinity measurements during the Gulf Stream Experiment”, Proc. Internat. Geosci. \& Remote Sens. Symposium, IGARSS-2000, VII, 2537-2542, Honolulu, HA., 2000b

11. Le Vine, D.M. and S. Abraham, "The effect of the ionosphere on remotes ensing of sea surface salinity from space: Absorption and emission at L-band", IEEE Trans. Geosci. Remote Sens., 40 (\#4), 771-782, 2002.

12. Le Vine, D.M. and S. Abraham, "Galactic noise and passive microwave remote sensing from space at L-band”, IEEE Trans. Geosci. Remote Sens., 42 (\#1), 119-129, 2004.

13. Li, F.K., W.J. Wilson, S.H. Yueh, S. Dinardo and S. Howden, 2000, Passive/active L/S band microwave aircraft sensor for ocean salinity measurements, Proc. Internat. Geosci. \& Remote Sens. Symp. IGARSS-2000, VII, 2547-2548, Honolulu, HA.

14. Reynolds, R.W. and T.M. Smith, "Improved global sea surface temperature analyses using optimum interpolation", J. Climate, 7, 929-948, 1994.

15. Sprintall, J. and M. Tomzcak, "Evidence of the barrier layer in the surface layer of the tropics", J. Geophys. Res., 97, 7305-7316, 1992.

16. Swift, C.T. and R.E. McIntosh, 1983, Considerations for microwave remote sensing of oceansurface salinity, IEEE Trans. Geosci. Remote Sens., 21, 480-491.

17. Thomann, G. C., "Experimental results of the remote sensing of sea-surface salinity at $21 \mathrm{~cm}$ wavelength", IEEE Trans. Geosci. Electronics, 14, 198-214. 1976.

18. Wilson, W.J.; Yueh, S.H.; Dinardo, S.J.; Chazanoff, S.L.; Kitiyakara, A.; Li, F.K.; Y. RahmatSamii, "Passive active L- and S-band (PALS) microwave sensor for ocean salinity and soil moisture measurements," IEEE Trans. Geosci and Remote Sensing, 39 (\# 5),1039-1048, 2001.

19. Yueh, S.H., R. West, W.J. Wilson, F.K. Li, E.G. Njoku, and Y. Rahmat-Samii, "Error Sources and Feasibility for Microwave Remote Sensing of Ocean Surface Salinity", IEEE Trans. Geosci and Remote Sensing, Vol 39, \#5, pp 1049-1059, May, 2001.

20. Yueh, S.H., W.J. Wilson, W. Edelstein, et al "Aquarius instrument design for sea surface salinity measurements", Proc. Internat. Geosci. \& Remote Sens. Symp. IGARSS-2003, Toulouse, France, 2003. 


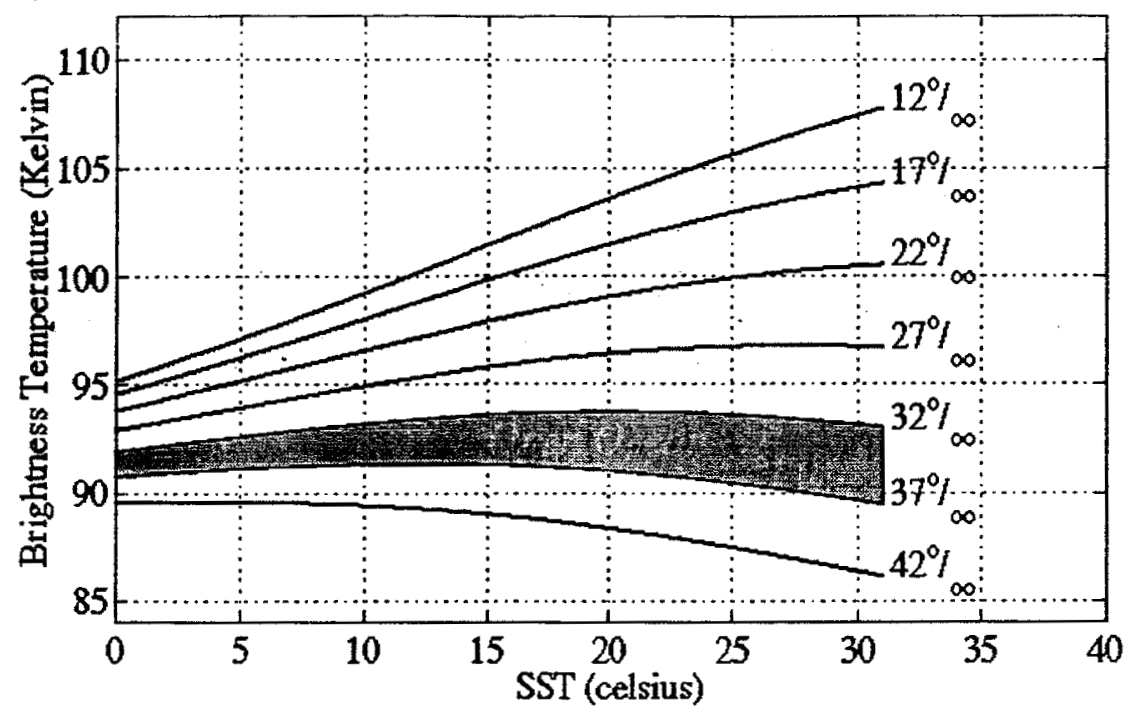

Figure 1: Level curves of constant salinity as a function of brightness temperature and water temperature at $\mathrm{L}$-band $(1.4 \mathrm{GHz}$ ). The curves are for an ideal surface (no roughness) at nadir and were obtained using the Klein and Swift (1978) model for the dielectric constant of sea water. The shaded area indicates conditions typical of the open ocean.

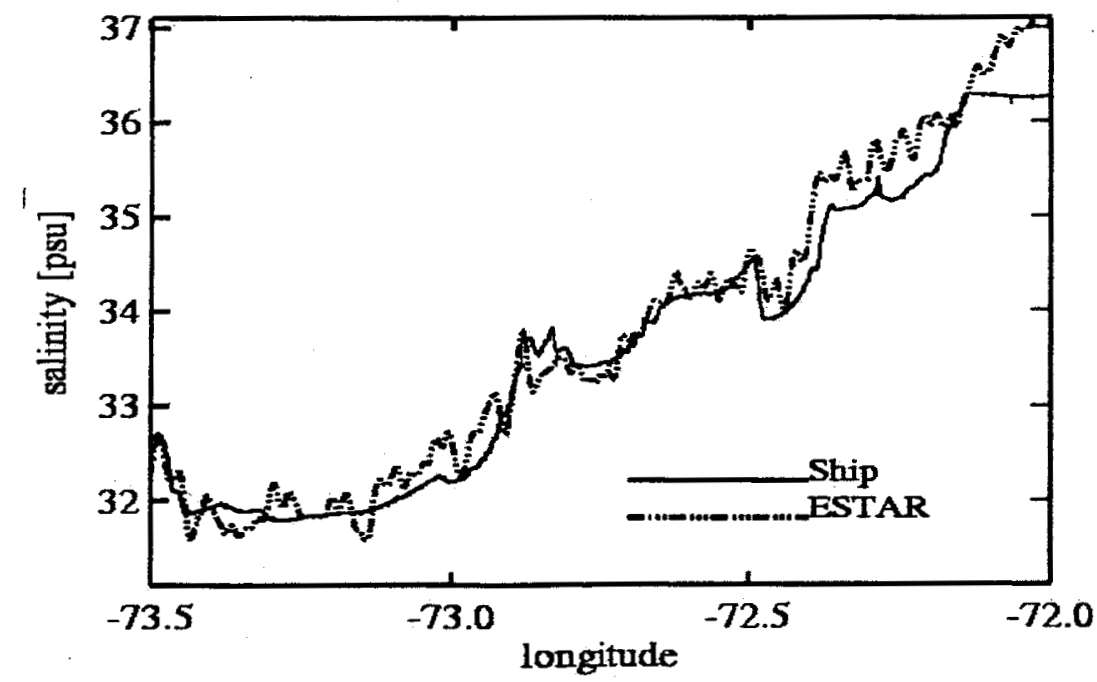

Figure 2: Comparison of sea surface salinity derived from ESTAR radiometer measurements (dashed curve) with surface measurements by the R/V Cape Henlopen during the Gulf Stream Experiment on August, 1999. 


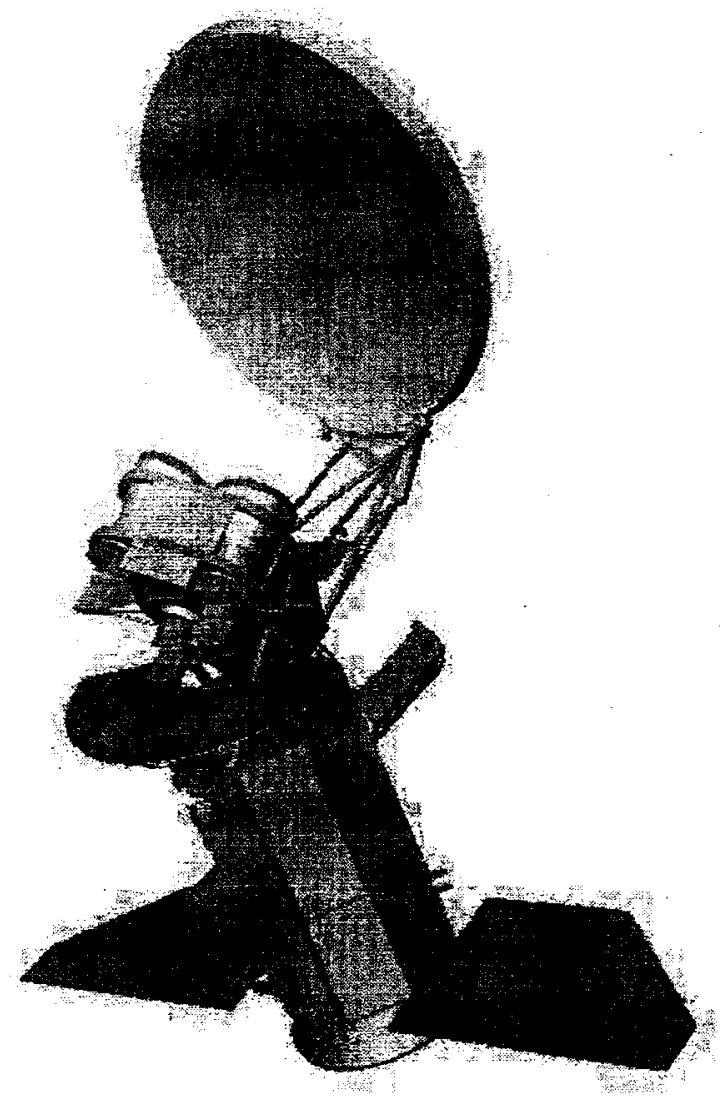

Figure 3: Artist's conception of the Aquarius/SAC-D sensor in the deployed position showing the reflector and feeds. In this view, the spacecraft flies left-to-right and the three beams point acrosstrack (out of the page). 